\title{
KRIMINAALIPOLIITTINEN PARADIGMA v. ABOLITIONISTINEN PARALOGIA - LYHYT ESITTELY
}

\begin{abstract}
"Kamppailulla vankiloita, rikosoikeudellista järjestelmää, poliisi- ja oikeusjärjestelmää vastaan on ollut jatkuva taipumus erkaantua niistä voimista, jotka olisivat mahdollistaneet kamppailun laajenemisen, koska se kehittyi 'eristyksissä' sosiaalityöntekijöiden ja exvankien keskuudessa. Kamppailun on vallannut naiivi, arkaainen ideologia, joka tekee rikollisesta samanaikaisesti toisaalta viattoman uhrin ja toisaalta täydellisen kapinallisen, toisaalta yhteiskunnan uhrilampaan ja toisaalta tulevien vallankumouksien nuoren suden. Tämä paluu viime vuosisadan lopun anarkistisiin teemoihin oli mahdollista ainoastaan siksi, ettei nykyisiä strategioita saatu yhdennettyä. Lopputulos on ollut perinpohjainen pesäero toisaalla tämän kampanjan monotoonisine, lyyrisine laulelmineen, jotka vain harvat kuulivat, ja toisaalla massojen välillä, joilla on hyvä syy olla hyväksymättä kampanjaa käyttökelpoiseksi poliittiseksi valuutaksi ja jotka myös antavat siunauksensa oikeudellisen ja poliisikoneiston säilyttämisen, jopa niiden vahvistamisen puolesta taukoamatta viljellyn rikollisuuden pelon johdosta." (Michel Foucault)
\end{abstract}

Suomalaisen kriminaalipolitiikan televisioteatterissa ovat osat merkillisesti vaihtuneet. Vankeinhoitojärjestelmässä toimivat virkamiehet esiintyvät varjokuvina, ääni teknisesti muunneltuna. $\mathrm{Ku}$ van alla olevassa tekstissä lukee: "Sari", vankeinhoitovirkailija. Samassa ohjelmassa vanki istuu kameran edessä luontevammin kuin monet toimittajat. Kuvaa ei ole manipuloitu, nimeä ei salata. Absoluuttisten laitosten kasvottomia esittävät tänään uudet näyttelijät.

Vankeinhoito kävi läpi ensimmäisen mediakriisinsä aikoihin. Kriisikeskustelu toisti kahta teemaa, jotka kietoutuivat julkisuudessa oudoksi kokonaisuudeksi. Eräät puheenvuorot painottivat vankeinhoidon sosiaalivaltiollisten tehtävien puutteellista täytän- töönpanoa tai jopa täydellistä laiminlyöntiä. Jälkihuolto on olematonta, kuntoutukseen ei keskitetä tarpeeksi voimavaroja jne. Toisaalla korostettiin lukuisia karkaamisia ja pakoyrityksiä, huumeiden käyttöä vankiloissa ja muita "rankaisuvaltiollisia" puutteita vankilajärjestelmässä.

Kriisikeskustelun yhteinen nimittäjä on luonteeltaan instrumentaalinen: katsotaan, että vankeinhoito ei kykene täyttämään yhteiskunnan sille asettamia tehtäviä. Tässä vankeinhoidosta (ja yleisestikin kriminaalipolitiikasta) käydyssä keskustelussa kritiikin liikkuma-ala on jo käsitteellisesti rajattu ahtaaksi. Rikosoikeudellinen järjestelmä on yhteiskunnallinen "objekti", jonka olemassaolo on yhteiskunnassa vaikuttavista subjekteista riippumaton.

\section{Mitä se on?}

Abolitionismi ${ }^{1}$ oli alunperin $\mathrm{Yh}$ dysvalloissa 1700- ja 1800-luvulla vaikuttanut orjuutta vastustanut liike, jonka johtajia oli valtiomiehenäkin vaikuttanut Benjamin Franklin. Abolitionistit järjestäytyivät puolueeksi, joka lakkautettiin tarpeettomana sisällissodan poistettua orjuuden vuonna $1870{ }^{2}$

Nykyisin abolitionismi tunnetaan parhaiten kriminaalipoliittisena terminä. Yleisin käyttöyhteys on ollut taistelu kuolemanrangaistuksen poistamiseksi, mutta abolitionismista puhuttiin esimerkiksi viitatessa toisen maailmansodan jälkeiseen "hoitoideologiaan", jonka mukaan repressiivisenä pidetyt rikosoikeudelliset rangaistukset oli korvattava inhimillisemmällä hoidolla. Nykyinen käyttöyhteys viittaa liikkeeseen, jonka tavoitteena on rikosoikeudellisen järjestelmän (ja erityisesti sen vapausrangaistuksiin perustuvan sanktiojärjestelmän) poistaminen tuomatta tilalle mitään korvaavaa. ${ }^{3}$

Ajatus rikosoikeudellisen järjestelmän poistamisesta ei ole uusi: varhaisin tunnettu tieteellinen esitys abolitionismista kriminaalipoliittisessa merkityksessään on ranskalaisen oikeustieteen tohtori Edouard Desprez'n kirja De l'abolition de l'emprisonnement vuodelta 1868. Tänä päivänä toimii kriittisen kriminologian ja kriminaalipolitiikan piirissä poliittisista aktivisteista, tutkijoista ja ex-vangeista koostuva ryhmä, joka identifioi itsensä abolitionismi-termin avulla.

Abolitionistien "virallinen" forum on ICOPA, International Conference on Penal Abolition. ICOPA:n ohjesääntöjen mukaan järjestön tavoitteena on rikosoikeudellisen järjestelmän täydellinen lakkauttaminen, mutta yksittäiset näkökulmat ja strategiat ryhmän sisällä vaihtelevat. ${ }^{4} \mathrm{Ku}-$ ten nimestä voidaan päätellä, ICOPA:n pääasiallisena tavoitteena on järjestää konferensseja, joissa abolitionistit voivat vaihtaa tietoa, suunnitella poliittista strategiaansa sekä tehdä politiikkaansa tunnetuksi. ${ }^{5}$ ICOPA:n piirissä toimivat abolitionistit eivät muodosta homogeenistä ryhmää. Abolitionismissa on nähtävissä tietty kaksijakoisuus mannerten välillä.

Pohjois-Amerikassa yhden tärkeän ryhmän abolitionisteja muodostavat kveekarit, jotka ovat uskonnollisen vakaumuksensa mukaisesti pyrkineet eri tavoin auttamaan yhteiskuntansa huono-osaisia. Kriminaalipolitiikassa kveekarit ovat vapaaehtoisvoimin toimineet erityisesti vapautuvien vankien auttamiseksi: taloudellinen ensiapu, turvakodit, työnvälitys, asunnonvälitys jne. Kveekareiden kanssa yhteistyössä toimii Quebecin maakunnassa Kanadassa L'Office des Droits des Defenu-e-s, joka on keskittynyt kuolemanrangaistuksen poistamiseen ja vankien ihmisoikeuskysymyksiin. Toimisto tekee tutkimusta, julkaisuja sekä toimii poliittisena painostusryhmänä kriminaalipoliittisissa kysymyksissä.

Toisen pohjoisamerikkalaisen erityisryhmän muodostavat alkuperäiskansojen (lähinnä intiaaniväestön) ja värillisen väestön edustajat. Intiaaniväestön suhde abolitionismiin pohjautuu toisaalta aat- 
teelliseen kysymykseen vapausrangaistuksesta erityisen dehumanisoivana sanktiomuotona. Toisaalta tämä suhde on poliittinen kysymys, sillä alkuperäisväestön osuus Pohjois-Amerikan vankipopulaatiosta on suhteettoman suuri. Värillisen väestön suhde abolitionismiin on luonteeltaan lähinnä poliittinen, mutta uskonnollisiakin painotuksia on havaittavissa.

Euroopassa abolitionistit ovat pesiytyneet yliopistoihin ja tutkimuslaitoksiin erityisesti Hollannissa ja Länsi-Saksassa, mutta myös Norjaa on pidetty abolitionismin "vahvana" alueena. ${ }^{6} \mathrm{Eu}-$ roopassa abolitionismi onkin muodostunut poliittisesti painottuneeksi kriittiseksi kriminologiaksi, joka nimenomaisesti omaksuu poliittiseksi tavoitteekseen rikosoikeudellisen järjestelmän poistamisen. Keskustelussa on anarkistisiakin piirteitä: kriittisen yhteiskuntaanalyysin rinnalla mm. Bakunin ja Kropotski esiintyvät usein lähdeluetteloissa.

Mannerten väliset eroavuudet ovat kehittyneet ikäväksi ja keinotekoiseksi teoria/praksis-jaoksi. Pohjoisamerikkalaiset syyttävät eurooppalaisia turhasta akateemisuudesta ja kykenemättömyydestä käytännön toimintaan. Eurooppalaiset puolestaan kritisoivat pohjoisamerikkalaisten tieto-opillista pohjaa sekä heidän toimintansa teoreettista itsetuntemusta. ICOPA:n piirissä on kuitenkin nähty yhdentymistä.

\section{Miten se voidaan oikeuttaa?}

Karkeana yleismääritelmänä abolitionismi on määriteltävissä kriittiseksi kriminaalipoliittiseksi suuntaukseksi, jonka perimmäisenä tavoitteena on rikosoikeudellisen järjestelmän poistaminen tuomatta tilalle vaihtoehtoisia ratkaisuja. ${ }^{7}$ Abolitionistisen strategian ydinkysymykseksi muodostuukin, miten rakenteita totaalisesti poistava näkökulma voidaan oikeuttaa. Esitän kaksi erilaista mallia. Toisessa pyritään hahmottamaan poliittisesti uskottavaa strategiaa; toi- sessa abolitionismia tarkastellaan diskursiivisena mallina, joka olisi strategisesti relevantti 1980-luvun poliittisessa ympäristössä.

Abolitionismi voidaan esittää poliittisena strategiana erittelemällä vapausrangaistuksiin perustuvan kriminaalipolitiikan tavoitteita. ${ }^{8}$ Rikosoikeudellisen järjestelmän pääasiallisena tehtävänä on yhteiskunnallisesti haitalliseksi katsotun käyttäytymisen estäminen. Erityisestävällä tasolla rikosoikeudellisella järjestelmällä (ja erityisesti vapausrangaistuksilla) oletetaan voitavan vaikuttaa yksittäisen lainrikkojan käyttäytymiseen tulevaisuudessa. Erityisestävyyden hypoteesi on osoitettu kestämättömäksi niin useasti, ettei virallinenkaan kriminaalipolitiikka siihen vetoa. Ainoa vapausrangaistuksen toimiva erityisestävä funktio on eristäminen, joka on virallisissa kannanotoissa hylätty poliittis-moraalisin perustein.

Yleisestävällä tasolla rikosoikeudellisella järjestelmällä oletetaan olevan yleistä yhteiskuntamoraalia luova ja ylläpitävä voima. Yleisestävyys on yksi rikosoikeustieteen ikuisuuskysymyksiä, jota ei ole koskaan voitu (eikä voida) verifioida. Yleisestävyys edellyttää käsitystä harkitsevasta, etuja ja haittoja tarkoin vertailevasta lainrikkojasta, joten verifioimattomanakin hypoteesinä se soveltuisi ainoastaan tietyn tyyppiseen rikollisuuteen. ${ }^{9}$ Lisäksi on erittäin epätodennäköistä, että jos esimerkiksi varkaus dekriminalisoitaisiin, niin yhteiskunnan yksityistä omistusoikeutta suojaava porvarillinen moraali romahtaisi. Kriminalisointi ja sanktiointi ovat usein tarpeettomia.

Preventiivisten funktioidensa rinnalla ns. modernin humaanin kriminaalipolitiikan tavoitteena pidetään myös poikkeavan käyttäytymisen sanktioinnista aiheutuvien haittojen oikeudenmukaista jakautumista. Ei vaadi suurta poliittista näkemystä havaita, että huono-osaisuus on suomalaisessa(kin) kapitalismissa kasautuvaa. Sanktiojärjestelmän piiriin joutu- vat ovat jo yhteiskunnalliselta statukseltaan kaikkein huono-osaisimpia, eikä rikosoikeudellisen järjestelmän tehtäviin kuulu yhteiskunnallisten hierarkioiden tasoittaminen. Haittojen oikeudenmukainen jakautuminen on virallisen kriminaalipolitiikan puolestapuhujien seminaariretoriikkaa, joka toimii (tehokkaasti) rikosoikeudellisen järjestelmän yhtenä legitimaatiomekanismina.

Edellisestä voidaan tehdä poliittinen johtopäätös. Rikosoikeudellinen järjestelmä on sekä tavoitteellisesti epäonnistunut ja turha että moraalisesti epäoikeudenmukainen ja ei-hyväksyttävä. Kriittisesti ajattelevan ja poliittisesti tietoisen ihmisen perusteluiksi järjestelmän olemassaolon tai säilyttämisen puolesta eivät riitä summittaiset viittaukset kulttuurihistoriallisiin tekijöihin ("juutalais-kristillinen perintömme") tai kansan oikeustajunnan raadollisuuteen. Abolitionismi poliittisena strategiana on tämän kanssa sopusoinnussa.

\section{Mitä se saattaisi olla?}

Suomalaisessa kriminaalipoliittisessa kulttuurissa saa hymisteleville yleisöille vapaasti esitellä "kriittisiä" strategioita ilman, että se velvoittaisi ketään poliittiseen toimintaan. Kansainvälisissä julkaisuissa suomalainen kriminaalipolitiikka kytketään mielellään "pohjoismaiseen kriittiseen traditioon"10, mutta kontrollin sisäinen immuniteettijärjestelmä torjuu yritykset puuttua päätettyihin tavoitteisiin. Torjuntamekanismit ovat kuitenkin yllättäviä: kriitikko syleillään hengiltä.

Jean Baudrillard ${ }^{11}$ puhuu politiikan aikakaudesta maailmana ennen mcluhanismia. Avainsana poikkeavuuden ymmärtämisessä politiikan aikakaudella oli anomia, vieraantuminen, jota ihminen pakeni rikollisuuteen, hulluuteen ja itsemurhiin. Politiikan aikakauden kriittinen strategia pyrki muuttamaan vieraantumisen perustaa, poliittista talousjärjestelmää. 
"Transpolitiikan" aikakauden, Baudrillardin nykyisyyden, avainsana on anomalia, täydellinen säännöttömyys, joka johtaa poikkeavuuteen ilman seurauksia. Anomisen poikkeavuuden normatiivinen konteksti oli laki, suuri elämää ohjaava apriori instituutio; anomaliassa poikkeavuus suhteutuu normiin, tilastolliseen keskiarvoon. ${ }^{12}$ Transpolitiikan anomaliset poikkeavuudet eivät pysty ylittämään vallan rajoja, sillä inhimillinen toimita on kutistettu tilastollisen yhtälön muotoon. Normaali, sovinnainen, lainkuuliainen tms. on ainoastaan tilastollisesti yleisin tapaus, poikkeavuus puolestaan moraalisesti ja poliittisesti merkityksetön demografinen erityistapaus. Poikkeavuuden ja sen kontrollin poliittisia ja moraalisia ulottuvuuksia korostavalle transpolitiikka on normipositivismin superlatiivinen muoto.

Baudrillardin tärkeä huomio on se, että sellainen yhteiskunta, jossa poikkeavuudelta puuttuu merkitys, on täydellisesti normalisoitu diktatuuri. Kun abolitionismi poliittisena strategiana omaksuu kontrollin tavoitteet annettuina, tyhjenee valtakin - poikkeavuuden ja sen kontrollin välisenä suhteena anomaliseksi naturalismiksi, jossa poliittiset rakenteet konstituoiva inhimillinen toiminta kuihtuu merkityksistä vapaaksi säännönmukaisuudeksi.

Transpolitiikan aikakaudella perinteinen poliittinen kritiikki on elimellinen osa uusintamisen kulttuuria. Transpoliittinen liberalismi tarvitsee kritiikkiä. Jotta porvarillisen demokratian fasadi säilyisi, on kriittistä diskurssia käytävä. Valta pystyy kriittisissä paneeleissa ja kotimaankatsauksissa osoittamaan poliittisen sietokykynsä ja parhaimmassa tapauksessa jopa dynaamisen potentiaalinsa. Poliittinen kritiikki on jussiparviaisten edistysajattelua, jossa "vaihtoehtoisuudesta" ja "radikalismista" on tullut esteettinen arvo, runonlausuntaa ilman poliittista sisältöä. Kritiikki (ja kriittinen politiikka) on transpolitiikan aikakaudella praksiksesta vapautettua teoreettista moniarvoisuutta.

Transpolitiikassa abolitionismi, pikemminkin taktisesti kuin moraalisesti oikeutettuna, on yksi keino kritiikin tukehtumiskuoleman torjumisessa. Vaatimalla rikosoikeudellisen järjestelmän poistamista abolitionismi kieltäytyy tarkastelemasta poikkeavuutta "yhteiskunnallisena ongelmana", johon on löydettävä ratkaisuja, kuten kriminaalipolitiikan paradigmat vaativat. Abolitionismi muodostaa kriittiselle kriminaalipolitiikalle sellaisen "paralogisen" (Lyotard) muodon, jossa kritiikin käsitteet, rakenteet ja tavoitteet eivät ole alistettavissa uusintamista palvelevalle "poliittiselle" dialogille.

Panu Minkkinen 
Viitteet

1. Sana tulee latinasta, ab-olere, kasvaa irti jostakin.

2. Yhdysvaltalaisessa kontekstissa abolitionismi on myös viitannut laillistetun prostituution vastustajiin.

3. Abolitionismi tunnistaa basaglialaisessa antipsykiatriassa serkun.

4. Suomessa on abolitionismille esitetty vaatimattomampia tavoitemäärittelyjä. Abolitionismi ei tarkoittaisi vapausrangaistusten yhtäkkistä ja totaalista poistamista vaan olisi pikemminkin ymmärrettävä kriminaalipoliittiseksi suuntaukseksi, joka pyrkii tietoisesti vapausrangaistuksen käytön minimointiin ja humaanien vaihtoehtojen kehittämiseen. Määritelmä ei eroa mitenkään virallisen suomalaisen kriminaalipolitiikan ns. ultima ratio -ajattelusta, jonka uskollisia kannattajia esim. vankeinhoito-osaston ylijohtaja $\mathrm{K}$. J. Lång on.

5. Tähän mennessä kolme kokousta on järjestetty: Torontossa, Amsterdamissa ja Montrealissa (kokouksia järjestetään joka toinen vuosi vuorotellen vanhalla ja uudella mantereella). ICOPA:n neljäs konferenssi järjestetään ensi vuonna Varsovassa. Liikkeen laajentumista sosialistisiin maihin pidetään ICOPA:n piirissä merkittävänä edistysaskeleena. Myös kehittyvien maiden edustajat ovat ilmaisseet kiin- nostusta järjestön toimintaa kohtaan.

6. Tunnettuja eurooppalaisia "akateemisia" abolitionisteja ovat mm. Louk Hulsman ja Herman Bianchi Hollannista, Sebastian Scheerer Länsi-Saksasta sekä Tony Ward Englannista. Abolitionistina on pidetty myös norjalaista Thomas Mathiesenia, joissakin kannanotoissa jopa poeettisen sosiaalidemokratian keulakuvaa Nils Christietä.

7. Ero muihin "humaaneihin" kriminaalipoliittisiin suuntauksiin näkyy esimerkiksi siinä, että abolitionistien keskuudessa suhtaudutaan varauksella sovitteluun, yhdyskuntapalveluun tai muihin "vaihtoehtoisiin" seuraamusmuotoihin, joiden vaikutus yhteiskunnallisen kontrollin kokonaisuuteen nähdään pikemminkin laajentavana kuin supistavana.

8. Suomalaisessa kriminologian ja kriminaalipolitiikan oppikirjassa nämä tavoitteet määritellään rikollisuudesta ja sen torjunnasta aiheutuvien haittojen minimoinniksi ja näiden haittojen oikeudenmukaiseksi jakamiseksi. Anttila, Inkeri Törnudd, Patrik: Kriminologia ja kriminaalipolitiikka. Juva 1983 , s. 124. On kuitenkin vaikeaa hahmottaa sellaista kriminaalipolitiikkaa, jonka nimenomaisena tavoitteena ei olisi preventio.

9. Esim. ns. valkokaulusrikollisuuteen, joka on minimaalinen osa ilmi tulevan rikollisuuden kokonaiskuvasta. Yleisestäyyden merkityksettömyys on eri- tyisen selvää törkeimpien rikosten osalta, joihin vedoten kovimmat äänenpainot järjestelmän puolesta esitetään esimerkiksi poliisiviranomaisten taholta.

10. Erityisen ansiokkaan kiiltokuvan suomalaisesta kriminaalipolitiikasta osana "vaihtoehtoista kriminaalipolitiikkaa Pohjoismaissa" antaa Lahti, jonka mukaan "ns. abolitionistisen suuntauksen" omaksuneiden tutkijoiden erimielisyydet "kriminaalipolitiikan asiantuntijoiden" kanssa ovat enemmän kuvitteellisia kuin todellisia. Lahti perustelee väitettään tavoitteiden samansuuntaisuudella, johon hän päätyy antamalla abolitionismille melko lattean ja rajallisen sisällön. Lahti, Raimo: Current Trends in Criminal Policy in the Scandinavian Countries, s. 59-72, kirjassa Scandinavian Criminal Policy and Criminology 1980-1985 (ed. by Norman Bishop).

11. Baudrillard, Jean: Les strategies fatales. Paris 1987, s. 37-39.

12. Esim. seksuaalisesti poikkeavista puhutaan nykyisin seksuaalisina vähemmistöinä. Termi peittää "kunnioittavasta" neutraalisuudestaan huolimatta (tai jopa siitä johtuen) alleen seksuaalisen epätasa-arvon todellisuuden. Myös kriminaalipolitiikan edistyksellisyyden mittana käytetään vankilukua, mikä tekee kontrollikoneiston olemassaolon "luonnolliseksi" välttämättömyydeksi. 